\title{
Maximizing the Value of a Business: Using the Right Metrics
}

\section{Don Sexton*}

Columbia Business School, Columbia University, New York, USA

The value of a business depends on its future not its past. Nonetheless, some managers base key decisions on backwards-looking metrics or models that have been shown to be inappropriate in many situations.

What metrics and models can provide managers with steering control for maximizing the value of their business? Here are some ideas.

While there are numerous books that discuss how to determine the value of a corporation, most of the metrics suggested do not provide a basis for predicting the financial impact of business decisions. Some analysts attempt to value businesses by focusing on various financial ratios calculated for prior time periods but that approach looks backwards. Other bases suggested for valuation include managerial talent, resources, innovation ability, and core competencies, but their effects on the value of a business are quite difficult to predict. Some managers rest their decisions on the hierarchy of effects model (also known as the "purchase funnel"), but scores of studies have shown that model is not applicable to many purchase situations.

To find metrics and models that can guide a manager in maximizing the value of any business, one needs to consider the main drivers of long-run business success. Economics shows that an organization's financial success over time depends primarily on how well they manage two factors: (1) perceived value - the value that a customer perceives they receive and (2) the costs of providing that value to the customer.

Perceived value is sometimes called "willingness to pay" and is not price but rather the maximum a customer will pay for a unit of a product or service. Relevant costs consist of the incremental or variable cost of providing the customer with a unit of the product or service.

Perceived value can be measured and predicted with a variety of statistical tools including value-in-use analysis, constrained choice modeling, and regression analysis. Variable cost information should be available through the accounting systems of companies.

Both perceived value and costs must be managed in concert. Some management gurus have suggested generic strategies where one focuses primarily on either value or costs. Such generic strategies often produce lop-sided strategies that simply do not work. If one tries to maximize customers' "delight," then costs may soar. If one keeps cutting costs (often a real temptation), one may well destroy customer value. Customer value and costs must be managed together not separately and must be in balance.

Customer value and costs are kept in balance by focusing on the difference between the perceived value to customers and the costs of providing that value. The difference between perceived value and cost per unit is known as Customer Value Added or CVA ${ }^{\circ}$, the subject of my book from Wharton School Publishing, Value Above Cost: Driving Superior Financial Results with $\mathrm{CVA}^{\oplus}$, the Most Important Metric You've Never Used. $\mathrm{CVA}^{\circ}$ is the value net of cost that a company produces for society. For example, if $\mathrm{CVA}^{\oplus}$ were negative for any length of time - the cost of the inputs being greater than the perceived value of the outputs - then a company would go bankrupt since the company would be destroying society's resources. As explained in Value Above Cost, managers that succeed in maximizing $\mathrm{CVA}^{\bullet}$ will succeed in maximizing the contribution of their business over time and, consequently, maximizing the value of their business.

Singapore Airlines succeeds in being one of the most profitable airlines in the world because they arguably have the highest $\mathrm{CVA}^{\circledR}$ in the airline industry - very high customer satisfaction coupled with very low costs. Zappos, the internet retailer, succeeds with very high $\mathrm{CVA}^{\circ}$ - they provide high value to their customers, such as free and fast shipping and a liberal return policy. Even though providing that value increases costs, the value to their customers increases even more than their costs.

Both of the key components of $\mathrm{CVA}^{\oplus}$ - perceived value and variable cost - can be predicted for any decision under review. Forecasting $\mathrm{CVA}^{\bullet}$ gives a manager steering control over their decisions. Decisions can be developed and selected based on objective analyses regarding their expected Return on Investment.

What is it worth to predict the financial impact of decisions before they are implemented? Most managers would say "a lot." Managers should know that it is possible to make such predictions accurately. In work with companies, $\mathrm{CVA}^{\oplus}$ alone predicted contribution with $\mathrm{R}$-squared values above 0.90 .

Managers, investors, and others concerned with managing the success of an organization should not look just at metrics such as traditional financial ratios that show where the business has been nor should they use limited models such as the purchase funnel. Managers need to employ forward-looking metrics such as $\mathrm{CVA}^{\circledR}$ that show where a business is going and that provide a sound foundation for making decisions that will lead to high likelihoods of achieving financial goals.

For comments or questions, Don Sexton can be reached at: des5@columbia.edu

*Corresponding author: Don Sexton, Columbia Business School, Columbia University, New York, USA, Tel: 1212219 8534; E-mail: donsexton@mindspring.com

Received February 03, 2014; Accepted February 04, 2014; Published February 11,2014

Citation: Sexton S (2014) Maximizing the Value of a Business: Using the Right Metrics. Bus Eco J 5: e102. doi: 10.4172/2151-6219.1000e102

Copyright: (C) 2014 Sexton S. This is an open-access article distributed under the terms of the Creative Commons Attribution License, which permits unrestricted use, distribution, and reproduction in any medium, provided the original author and source are credited. 